\title{
Evaluation of "SIBS", An Intervention for Siblings and Parents of Children with Chronic Disorders
}

\author{
Yngvild Bjartveit Haukeland $\mathbb{1}^{1} \cdot$ Nikolai Olavi Czajkowski $^{1} \cdot$ Krister Westlye Fjermestad $^{1,2} \cdot$ Wendy K. Silverman $^{3} \cdot$ \\ Svein Mossige ${ }^{1} \cdot$ Torun Marie Vatne ${ }^{2}$
}

Published online: 6 June 2020

(c) The Author(s) 2020

\begin{abstract}
Siblings of children with chronic disorders are at increased risk of experiencing family communication problems and poorer mental health. We assessed initial feasibility, acceptability, and outcomes of SIBS; a manual-based group intervention for siblings and parents of children with chronic disorders, aiming to improve parent-sibling communication and sibling mental health. Ninety-nine siblings aged $8-16$ years $(M=11.5$ years, $S D=2.0 ; 54.5 \%$ girls $)$ and parents $(63.6 \%$ mothers $)$ of children with chronic disorders participated in three separate group sessions for siblings and parents and two joint sessions with integrated sibling-parent dialogues. We assessed participant satisfaction post-intervention and checked for group leader manual adherence. We measured the following outcomes at baseline, three, and six months post-intervention in an open trial: (1) parent-sibling communication quality; (2) sibling emotional and behavioral problems; (3) sibling adaptation to the disorder; and (4) sibling disorder knowledge. Using growth curve modeling, we found significant improvement in parentsibling communication quality $(\mathrm{p}=0.001)$, emotional and behavioral problems $(\mathrm{p}=0.009)$, adaptation to the disorder $(\mathrm{p}=$ 0.003 ), and disorder knowledge $(\mathrm{p}=0.000)$ from baseline to follow-up (effect sizes $d=0.22$ to 0.64 ). Improvement in sibling-reported emotional and behavioral problems and adaptation to the disorder was partly explained by communication quality. User satisfaction was high and manual adherence was good. Our evaluation yields support for the SIBS intervention, with initial evidence of acceptability, feasibility, and beneficial outcomes. Our study suggests targeting parent-sibling communication may be a beneficial way of improving siblings' mental health.
\end{abstract}

Keywords Siblings as next of kin $\cdot$ Parent-sibling communication $\cdot$ Sibling mental health $\cdot$ Sibling intervention $\cdot$ Chronic disorders

\section{Highlights}

- SIBS is a novel five-session intervention for siblings as next of kin.

- An open trial showed beneficial sibling outcomes after participating in SIBS.

- Both siblings and parents reported high satisfaction with SIBS.

- Involving parents actively may be key to sibling interventions.

- Targeting parent-child communication may represent useful sibling support.

Yngvild Bjartveit Haukeland

yngvild.haukeland@psykologi.uio.no

1 Department of Psychology, University of Oslo, P.O Box 1094 Blindern, 0317 Oslo, Norway

2 Frambu Competence Center for Rare Disorders, Sandbakkveien 18, 1404 Siggerud, Norway

3 Department of Psychology, Yale University, Box 208205, New Haven, CT 06520-8205, USA
A chronic disorder (CD) affects intellectual and/or physical functioning and is characterized by prolonged duration and no spontaneous or complete cure (Stanton et al. 2007). The United Nations Children's Fund (2013) has estimated that one in 20 children lives with a CD. Many children with CDs have typically developing siblings (herein: siblings). Siblings may be exposed to difficult and challenging experiences such as parental absence due to hospitalizations, behavior problems displayed by the child with $\mathrm{CD}$, differential parental treatment, and witnessing medical 
emergencies (e.g., Knecht et al. 2015). Although siblings do not necessarily meet criteria for clinical diagnoses, a metaanalysis showed they are at increased risk of emotional and behavioral problems compared to controls (Vermaes et al. 2012). Due to these multiple risks, siblings may need interventions.

Existing sibling interventions typically involve group sessions focused on the sibling experience, often combined with social-recreational activities. Several studies have documented positive outcomes for siblings' psychological well-being, stress, self-esteem, social support, and sibling relationships (e.g., Lobato and Kao 2005; Smith and Perry 2005; Williams et al. 2003). These are important and promising initial findings. However, no sibling intervention qualifies as "well-established", in terms of controlled designs, sufficient sample sizes, and sufficient descriptions of session contents (Hartling et al. 2014; Tudor and Lerner 2015). Many existing interventions are also time-consuming for strained families, requiring participation in sessions with duration from twelve up to $20 \mathrm{~h}$ (e.g., Cooke and Semmens 2010; McCullough and Simon 2011). Furthermore, many previous sibling interventions studies have included no parental involvement or have provided limited descriptions of the parental component (Tudor and Lerner 2015). These are important limitations, given that CDs affect the entire family system, and that parental behaviors and attitudes may be key to understand and relieve siblings' emotional distress (Incledon et al. 2015; Lobato and Kao 2002; Taylor et al. 2001). Furthermore, no previous intervention has explicitly addressed family communication. This is surprising, given that $\mathrm{CDs}$ in children have been associated with poorer family communication (Murphy et al. 2017), and given the documented links between family communication and children's adjustment (e.g., Barnes and Olson 1985; Jackson et al. 1998).

Many of the risks siblings are exposed to are inevitable due to the nature of the $\mathrm{CD}$. Thus, identifying and targeting modifiable factors to improve mental health and adaptation in siblings is crucial. The main aim of the current intervention is to improve parent-sibling communication, for three main reasons. First, siblings experience a range of different and often contradictory emotions in relation to the CD (Brennan et al. 2012; Haukeland et al. 2015; Knecht et al. 2015). Contradictory emotions are difficult for children to comprehend (e.g., Aldridge and Wood 1997; Zajdel et al. 2013), and adult support is beneficial to make sense of such experiences. Children's psychosocial adjustment is related to their parents' ability to label, validate, and encourage children to talk about emotions (e.g., Fivush 2007; Gentzler et al. 2005). Thus, open parent-child communication may increase siblings' emotion sharing, develop siblings' emotional understanding, and potentially lead to more adaptive problem solving and coping strategies (e.g.,
Fivush 2007; Gentzler et al. 2005). However, a recent metaanalysis identified that communication in families of children with CDs is characterized by lower levels of warmth/ structure and higher levels of hostility/intrusiveness/withdrawal compared to families of typically developing children (Murphy et al. 2017). Siblings also often report to cope with emotional experiences alone rather than seek support from others (Brennan et al. 2012; Haukeland et al. 2015). Compared to controls, siblings have been found to be less aware of emotions and less willing to tell parents about difficult emotions, which in turn is related to more emotional and behavioral problems (Long et al. 2013). In line with this, we argue that targeting parent-sibling communication may help siblings share their emotional experiences and help parents provide emotional support, which in turn may improve siblings' emotional and behavioral functioning and adaptation.

A second reason to target parent-sibling communication is its' importance for siblings' understanding of their brother or sister's CD. Siblings often have limited, misleading, and/or incorrect knowledge about the $\mathrm{CD}$, and poorer CD-knowledge is associated with poorer sibling adjustment (e.g., Lobato and Kao 2002; Vatne et al. 2015). Increased CD-knowledge in children has been found to reduce anxiety and improve perception of control and adaptation (e.g., Houtzager et al. 2001; Riekert et al. 1999). For example, improved CD-knowledge may make it easier to explain the $\mathrm{CD}$ and $\mathrm{CD}$-related behaviors to peers. Without sufficient information, siblings tend to rely on their own interpretations, which may be misleading or even disruptive (Vatne et al. 2015). Given that parents are siblings' main source of CD-information, supporting parents in communication about the $\mathrm{CD}$ may therefore benefit siblings.

Finally, targeting parent-sibling communication is important given that parenting a child with $\mathrm{CD}$ is associated with more parental stress, burnout symptoms, and depression compared to norms (e.g., Cousino and Hazen 2013; Singer 2006). These problems may reduce parents' capacity for attentive listening, which limits parental abilities of relating to and empathizing with siblings' experiences (e.g., Cicchetti and Toth 1998; Incledon et al. 2015). Furthermore, children are often sensitive to their parents' distress (e.g., Hilton and Gustavson 2002; Lucas-Thompson et al. 2017). Thus, siblings may be reluctant to share emotional challenges with their parents not to add to their parents' strain. Hence, helping siblings share emotions and provide families with opportunities to communicate is important and may increase parental informative and emotional support to siblings.

Herein, we present initial evidence from an open trial of a joint parent-sibling intervention (SIBS; short for siblings; Vatne et al. 2019) that focus on parent-sibling 
communication. SIBS is a five-session manual-based program comprising separate group sessions for siblings and parents and joint sibling-parent sessions. The objectives of SIBS are to strengthen parent-sibling communication and empower parents to provide informational and emotional support to siblings. To assess initial acceptability and feasibility of the SIBS intervention, we measured sibling and parent satisfaction with the intervention and group leader adherence to the manual. We measured outcomes at baseline (T1), three months (T2) and six months (T3) after participation in SIBS. Parent-sibling communication is the primary outcome. Secondary outcomes are sibling emotional and behavioral problems, adaptation to the $\mathrm{CD}$ and CD-knowledge. Based on existing evidence, we argue these secondary outcomes may be modified through the improvement of parent-sibling communication quality (e.g., Gentzler et al. 2005; Incledon et al. 2015; Lobato and Kao 2002).

The main research questions are: (1) How was the intervention perceived by participants?, (2) To what degree did group leaders adhere to the manual?, (3) Does the quality of parent-sibling communication improve from preintervention to 6-months post participating in SIBS?, (4) Do the secondary outcomes of emotional/behavioral symptoms and adaptation to the $\mathrm{CD}$ decrease, and does $\mathrm{CD}$-knowledge increase from pre-intervention to 6-months post participating in SIBS?, and (5) Can improvements in the secondary outcomes be accounted for by the quality of parent-sibling communication? We expected parent-sibling communication and secondary outcomes to improve from baseline to post-intervention. We also expected that improvement in the secondary outcomes would be associated with quality of parent-sibling communication.

\section{Method}

\section{Participants}

The sample comprised 99 siblings aged 8 to 16 years $(M=$ 11.5 years; $S D=2.0 ; 54.5 \%$ girls), each participating together with one parent in the SIBS intervention (i.e., biological mother (63.6\%), biological father (31.3\%), adoptive father (3.0\%), or stepmother $(2.0 \%)$ ). Both parents did however complete the questionnaires. Mean parental age was 40.9 years for mothers $(S D=4.9$ years; range $=$ $31-53)$ and 43.8 years for fathers $(S D=5.5$; range $=$ 34-59). See Table 1 for further demographics and parents' subjective evaluation of the family economy. All participating siblings had a brother or sister with a CD. The children with CDs were aged 3 to 21 years ( $M=10.4$ years; $S D=4.3 ; 45.0 \%$ girls). See Table 1 for overview of their diagnoses. The rare diagnoses were categorized as either
Table 1 Participant background information

\begin{tabular}{lc}
\hline & Percent \\
\hline Diagnosis of child with CD & \\
RD mainly involving intellectual impairment & 29.3 \\
Autism spectrum disorders & 25.3 \\
RD mainly involving physical impairment & 23.2 \\
Congenital heart disease & 12.1 \\
Down syndrome & 7.1 \\
Cerebral palsy & 3.0 \\
Sibling relationship order & \\
Siblings older than child with CD & 59.8 \\
Family constellations*: & \\
Parents of sibling living together ${ }^{\mathrm{a}}$ & 76.5 \\
Parental education (\% with $\geq 4$ years of higher education) & \\
Paternal education** & 27.3 \\
Maternal education & 39.4 \\
Family economy*** & \\
"Good" & 57.9 \\
"Neither good nor poor" & 29.5 \\
"Poor" & 8.4 \\
"Varying a lot" & 2.1 \\
\hline
\end{tabular}

$C D$ chronic disorder, $R D$ rare disorder, including: Angelman syndrome, Becker muscular dystrophy, Bethlem myopathy, Chromosome $5 \mathrm{q}$ deletion syndrome, Congenital muscular dystrophy, Cri-duchat syndrome, Duchenne muscular dystrophy, Fragile X syndrome, Friedreich's ataxia, Hereditary ataxis, Humoral immune deficiency, Klinefelter syndrome, Neurodegenerative disease, Neurofibromas type 1, Noonan syndrome, Osteogenesis imperfecta, Prader-Willi syndrome, Smith-Magenis syndrome, Spinal muscular atrophy, Velocardiofacial syndrome

$* / * * / * * *$ Information missing in one, two, or four cases, respectively

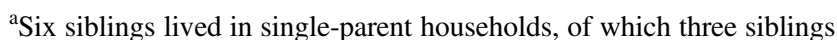
had a deceased parent. Remaining percentage corresponds to siblings with parents not living together with shared child caring

involving mainly intellectual or physical impairment. The mean number of children per family was $3.1(S D=1.0)$ and $71.1 \%$ of participants had more siblings in addition to the child with a CD. Ethnicity was not registered, however the vast majority was Caucasian.

\section{Procedures}

We recruited participants from six sites providing services to families from all regions of Norway; two national specialist disorder centers for rare disorders and autism spectrum disorders and four national user associations for autism spectrum disorders, cerebral palsy, congenital heart disease, and Downs's syndrome in Norway. We preselected family courses and camps in different regions of Norway that were scheduled by these six sites to ensure a balanced distribution between CDs characterized by mainly intellectual or physical impairment. Further, all sites represented settings 


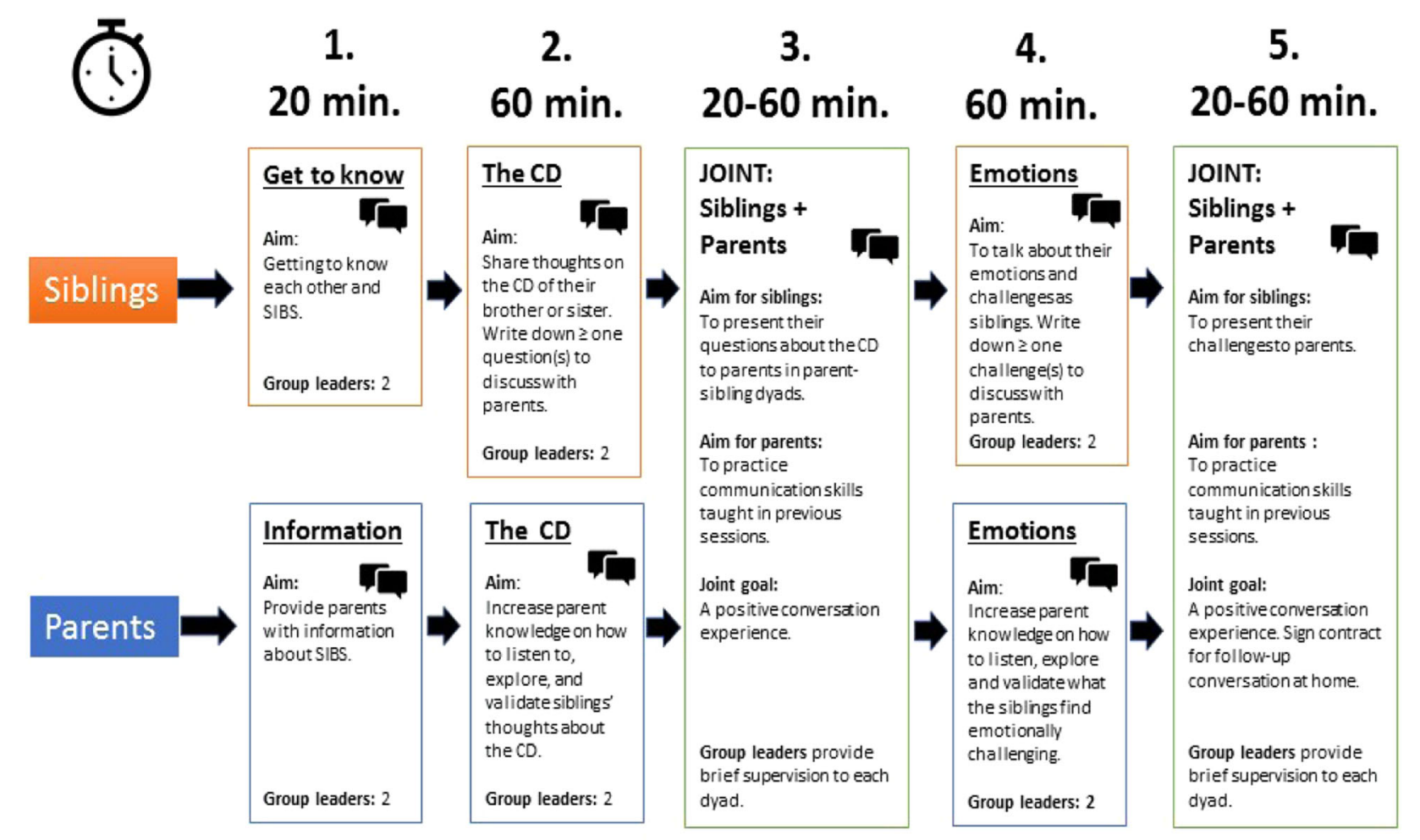

Fig. 1 The SIBS intervention: session content and aims. CD chronic disorder. The timeframe of the sessions (minimum two days, maximum five days) was flexible, i.e. they were either delivered as daily

in which families of children with the included CDs naturally gathered and had a timeframe that allowed for implementation of the SIBS intervention (see Fig. 1 below). All courses/camps had a minimum of two overnight stays for the families and the SIBS intervention was part of a larger camp/course program otherwise comprising lectures for parents about CD-related topics and social/recreational activities for all family members. Of families accepted for the courses/camps, we invited those with at least one typically developing sibling aged 8 to 16 years to take part in the study through an information letter, with separate versions for parents and for siblings. If the sibling and/or the parent had a $\mathrm{CD}$, they were not invited to participate in the study. Written informed consent was obtained, and families were informed that participation was voluntary and would not affect current or future course/camp participation. No financial incentives were offered. The study was approved by the local institutional board for research ethics.

See Fig. 2 for participant flow. Families reported different reasons for declining: (1) the sibling did not want to participate $(n=7)$; (2) participation not possible due to logistics $(n=5)$; (3) parents did not want this kind of intervention in a setting with a primarily social focus (i.e., a weekend camp) $(n=2)$; (4) the sibling had a diagnosis him-/herself (not known to the project group at the time of recruitment) $(n=1)$; and (5) the diagnosis of the child with sessions or with session 1-3 and session 4-5 on two separate days, depending on the length of the course/camp and in order to fit with the overall program

CD being too new for the family $(n=1)$. In the remaining cases, parents did not provide any reason for declining. At $\mathrm{T} 1$, parents and siblings $>11$ years of age received questionnaires and instructions by postal mail approximately one week prior to the course/camp. Siblings $<11$ years filled out the $\mathrm{T} 1$ questionnaires at site, under the assistance of a project assistant. At $\mathrm{T} 2$ and $\mathrm{T} 3$, we sent questionnaires by postal mail to parents and all siblings. We encouraged parents to let the siblings fill out the forms by themselves and to contact the project group if they had questions. To prevent dropout, we sent SMS reminders before the followup time points.

Twenty-two groups were conducted with three to seven sibling and parent participants in each group $(M=4.2)$. The maximum age gap within each sibling group was set to three years, to adapt group discussions of emotions, thoughts, and behaviors to participants' developmental levels. All groups were led by two group leaders (i.e., three clinical psychologists, one special educator, or seven advanced clinical psychology students). Due to parallel program at the courses/camps (i.e., lectures for parents), only one parent (63.6\% mothers) from each family participated in SIBS. The decision about which parent was left to the families. In cases where two siblings from the same family participated $(n=13)$, both parents were encouraged to participate but had to remain in the same parent-sibling 
Fig. 2 Study flowchart. *In six cases $(3.0 \%)$, it was not registered whether the families did not respond or actively declined. **Eight of these families were not offered SIBS because the intervention was canceled due to too few accepting families $(<3)$ for that particular course or camp

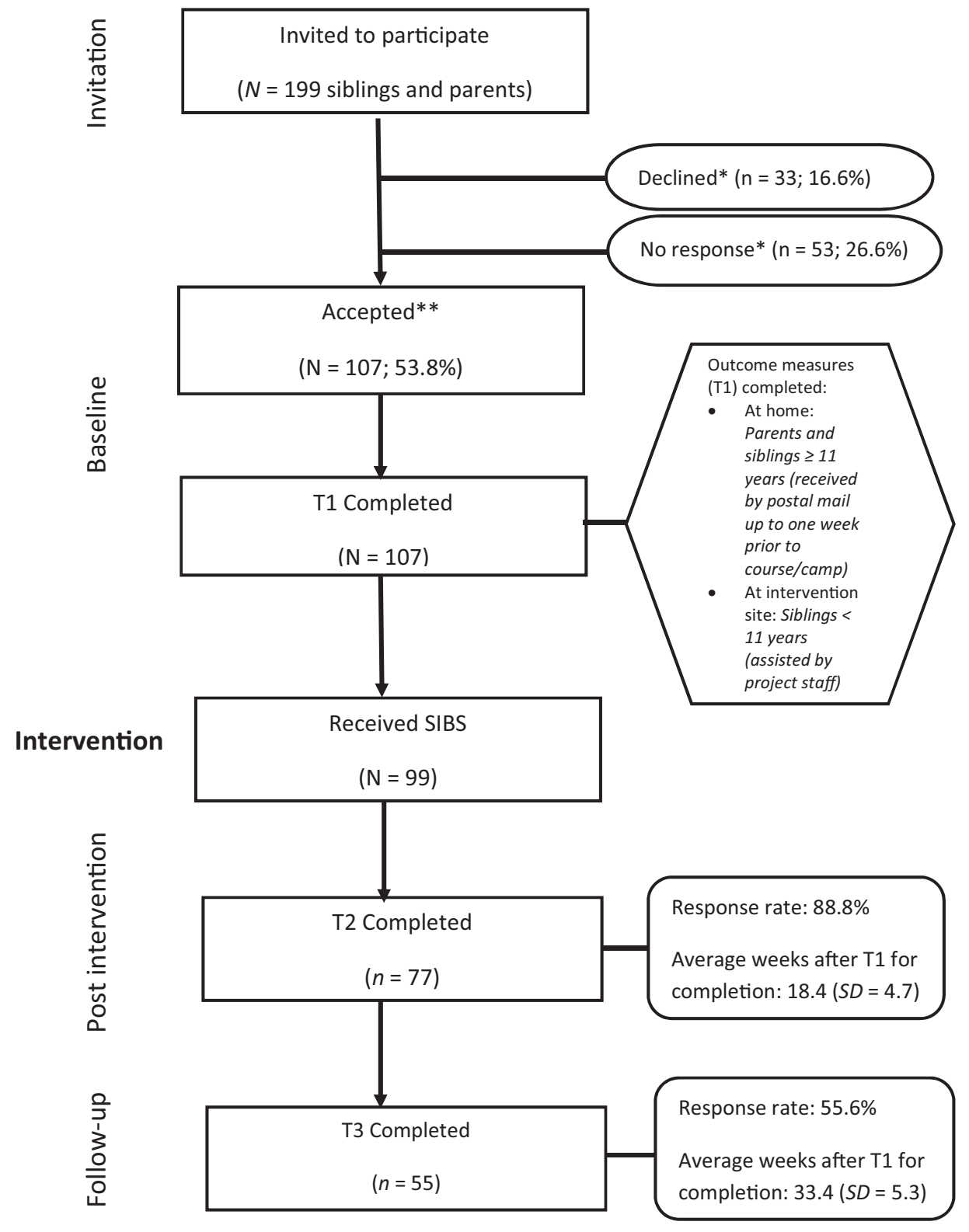

dyads throughout the intervention. Of the participating families, only one family explicitly withdrew from the study post-intervention due to time constraints. The remaining families were lost to follow-up of unknown reasons.

\section{Intervention Manual}

The SIBS manual is based upon previous research on sibling mental health and on group interventions for children and youth, clinical experiences, and user voices. A manual was developed through several steps prior to the study and is described elsewhere (Vatne et al. 2019). SIBS comprises five sessions (see Fig. 1) organized as three parallel sessions for parents and siblings and two joint sibling-parent sessions. Interaction between the parent and the sibling group is a key element. In sessions 2 and 4, siblings prepare questions about the CD (session 2) and identify emotional challenges (session 4), which are presented to the parent group by one of the sibling group leaders. In addition, siblings prepare individual questions and challenges that are discussed in parent-sibling dyads in sessions 3 and 5, respectively. At the end of session 5, a contract for a follow-up 
conversation when arriving home is signed. The focus of the intervention is to strengthen the quality of parent-sibling communication through increasing parental listening, exploration, and validation of the siblings' experiences related to their situation as a brother or sister to a child with a CD.

Each SIBS session has a set of mandatory manual items. To examine adherence, the manual developers used a manual checklist to rate video recordings of six interventions (i.e., $27.3 \%$ of total interventions; representing all group leaders) in terms of manual items covered in sessions.

\section{Measures}

\section{User acceptability}

We measured participant satisfaction with an evaluation form developed for the current study. Siblings and parents rated their experience with SIBS immediately after session 5 (i.e., on site). Siblings rated importance and benefit of SIBS on a scale from 1 (not important/useful) to 10 (very important/useful), and their overall satisfaction with SIBS on a scale from 1 to 4 where 4 reflects high satisfaction. Parents rated the degree to which the aims of SIBS were attained, on a scale from 0 (not met) to 4 (highly met). Anonymity in responses was ensured during completion and participants left the evaluation forms in piles (i.e., they were not handed to group leaders).

\section{Primary outcome}

We used the child version of Parent-Child Communication Scale (PCCSc; Conduct Problems Prevention Research Group 1994) to measure quality of parent-sibling communication. The 5-item "parent communication" subscale of the PCCSc was used in the present study. Siblings rated openness and problems in parent-sibling communication on a 5-point scale from 1 (almost never) to 5 (almost always) (e.g.; "Does your mother try to understand what is on your mind?") regarding the parent who participated in SIBS. Satisfactory reliability has been reported for the PCCSc $(\alpha=0.75$; Pek 2006; McCarty and Doyle 2001). In the present study, internal consistency of the parent communication subscale of PCCSc was satisfactory ( $\alpha=0.63$ to 0.82 ).

\section{Secondary outcomes}

We used the Strengths and Difficulties Questionnaire (SDQ; Goodman et al. 2000) to assess siblings' emotional and behavioral problems. Siblings rated emotional, conduct, attention, and peer problems on a 3-point scale from 0 (not true) to 2 (certainly true) (e.g.; "I worry a lot") on the 25item total self-report SDQ (SDQ-S). We included parents' ratings of siblings' emotional and behavioral problems using the SDQ parent report (SDQ-P). Adequate test-retest reliability, concurrent validity, and the ability to distinguish between community and clinical samples has been reported for the SDQ ( $\alpha=0.80$; Goodman 2001; Goodman and Scott 1999; Vostanis 2006). In the present study, internal consistency on the SDQ-S was satisfactory ( $\alpha=0.77$ to 0.82 ). For SDQ-P, internal consistency was satisfactory for fathers ( $\alpha=0.75$ to 0.82 ) and mothers $(\alpha=0.75$ to 0.87 ) on all time points.

To measure sibling adaption to the $\mathrm{CD}$, we used the Negative Adjustment Scale (NAS; Lobato and Kao 2002; Sahler and Carpenter 1989). The 18 -item NAS is a modified version of the Sibling Perception Questionnaire (SPQ; Sahler and Carpenter 1989). Siblings rated interpersonal relationships, intrapersonal responses, fear, and communication about the $\mathrm{CD}$ on an unnumbered 4-point scale from "never" to "a lot" (e.g.; "I feel angry because of my brother or sister's disability or illness"). Higher scores reflect more negative sibling adaptation to the CD. Satisfactory internal consistency has been reported for the NAS $(\alpha=0.79$; Lobato and Kao 2002). In the present study, internal consistency on NAS was satisfactory ( $\alpha=0.69$ to 0.76 ).

To assess siblings' CD-knowledge, we used the Sibling Knowledge Interview (SKI; Lobato and Kao 2002). The level of CD-explanation was used in the present study. Trained interviewers (members of the project group and research assistants) asked siblings to explain the $\mathrm{CD}$ of their brother or sister in terms of symptoms, cause, and treatment. The SKI was administered either face-to-face (T1; at site prior to SIBS) or by phone (T2, T3). All interviews were tape-recorded. Siblings' responses were scored from 1 (no understanding) to 5 (accurate knowledge) according to the scoring system developed by Lobato and Kao (2002). Three trained project assistants (independent of interviewers) scored the SKIs, and obtained a satisfactory interrater reliability ( $\alpha=0.68$ to 0.87 ).

\section{Data Analyses}

Bivariate Pearson correlations between all sibling-reported outcome variables across all time points (T1-T3) are given in Table 2. We expected substantial within-group variation on the outcome measures in our sample as it was a nonclinical sample with considerable variation in CDs, and as sibling status and age were the only inclusion criteria for participation. Consequently, growth curve modeling was chosen to make us able to investigate both within-subject changes over time and between-subject variation. In addition to evaluate changes in mean scores at the group level over time, we also wanted to investigate the individual growth trajectories (Gelman and Hill 2007). A further advantage of this approach is that it enables inclusion of 


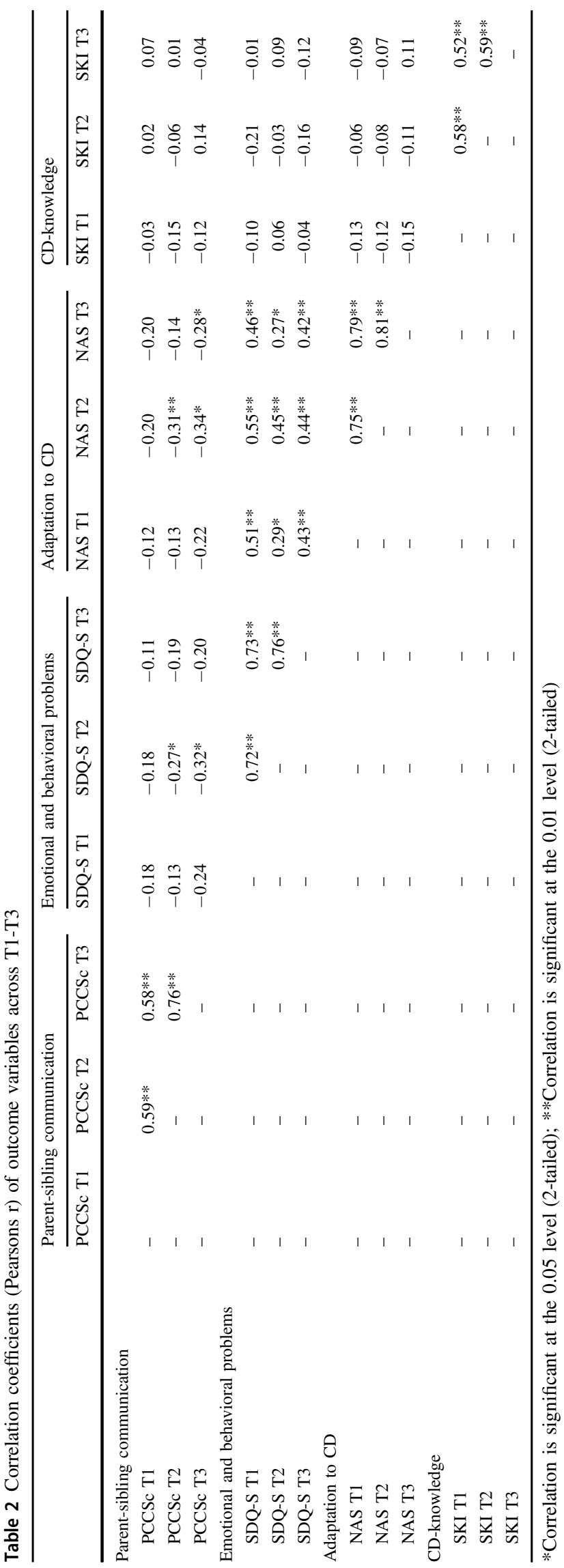

individuals with partial data (Heck and Thomas 2015), which is an advantage in longitudinal studies where missing data is common. We investigated variances in both intercept (estimated initial status at baseline) and slopes (estimated change in outcome measures over time). First, we examined a growth curve model for our primary outcome variable, parent-sibling communication (PCCSc). We conducted growth curve analyses in a number of stages. In a first baseline model (Model 1a), only a random intercept was included. In a second model (Model 2a), we added a linear effect of time. Then, we added gender of the participating parent as a covariate (Model 3a) to investigate a possible effect of the parent being a mother or father on the communication variable.

For the three remaining outcome variables, (SDQ-S/SDQ$\mathrm{P}$, NAS, and SKI), we conducted separate growth curve analyses in the following procedure: Model $1 \mathrm{~b}$ and Model $2 \mathrm{~b}$ were estimated in the same way as with the primary outcome variable. Then, we included parent-sibling communication (PCCSc) as a time-varying covariate (Model 3b), to investigate whether siblings' levels of mental health problems and/or the quality of their explanations of their brother or sister's CD could be partly explained by perceived quality of communication with the participating parent. Finally, we added siblings' age and gender as fixed covariates (Model 4b) to assess possible associations with the individual trajectories over time. The overall best model was chosen based on the Akaike Information Criterion (AIC) (Akaike 1974). Models were fitted by means of the Maximum Likelihood (ML) estimator, with an unstructured covariance structure for the random effects. The time variable was coded as 0,1 , or 2 corresponding to the assessment waves (baseline (0), three (1) and six months (2) after). Data were analyzed using IBM SPSS, version 25 (IBM Corp 2017).

When significant changes were seen, we calculated effect sizes by applying Cohen's $d$ and corresponding indicators for small $(d=0.2)$, medium $(d=0.5)$, and large $(d=0.8)$ effect sizes (Cohen 1988). We investigated intraclass correlation (ICC) to examine possible clustering of data at intervention level, as SIBS was delivered in contexts that varied across the data collection in terms of setting, number of sibling participants in the group, group leaders, and type of CDs of the participants' siblings. All ICC coefficients were $<0.25$, an identified cut-off by Guo (2005) for indications of nesting. As such, we did not find any reason to investigate cluster-specific intercepts and slopes.

In terms of missing data, $44.4 \%$ of participating families were lost to follow-up (T3) for unknown reasons. Examination of selective attrition showed no significant differences in socio-economic status or baseline scores for the four outcome measures. Furthermore, Little's (1986) MCAR tests indicated data were missing completely at random. 


\section{Results}

\section{Participant Satisfaction and Adherence}

Mean score on overall satisfaction with the SIBS intervention among siblings was $3.5(S D=0.6$; range $2-4)$, indicating high satisfaction. The mean score for perceived importance of the intervention among siblings was 8.1 ( $S D$ $=1.9$ ), and for perceived utility on the same scale the mean score was $8.2(S D=1.9)$, both reflecting very high satisfaction. Parents gave a mean score of $3.4(S D=0.7$; range 1-4) when asked about their overall satisfaction with SIBS. Further, parents gave mean scores on the subscales ranging from 3.0 to 3.3 when rating whether they regarded that they had obtained: (1) increased competence in talking to siblings about the $\mathrm{CD}(M=3.0 ; S D=1.0)$; (2) increased insight into siblings' CD-knowledge and challenges $(M=$ 3.2; $S D=1.0$ ); and (3) increased parent-child communication $(M=3.3, S D=0.9)$. Altogether, parents' scores reflected high approval of the intervention.

Regarding group leaders' adherence to the intervention manual, average fidelity per intervention was $85.6 \%$ (range $78.7 \%-93.9 \%)$.

\section{Correlations between Outcome Variables}

See Table 2 for correlations between the sibling-reported outcome variables at all time points (See Appendix A for a complete table including parent report). Parent-sibling communication (PCCSc) was negatively correlated with sibling-reported emotional and behavioral problems (SDQ$\mathrm{S})$ and difficulties in adaptation to the CD (NAS), significantly so at some assessment points. This indicates that lower quality in parent-sibling communication is associated with higher levels of self-reported mental health problems in siblings. SDQ-S/P and NAS were significantly positively correlated at all time points. However, the correlations were significant only at $\mathrm{T} 2$ and $\mathrm{T} 3$ for mother report, and at $\mathrm{T} 1$ and $\mathrm{T} 2$ for father report.

\section{Growth Curve Modeling of Change over Time}

See Fig. 3 for spaghetti plots of all sibling-reported outcome variables. These plots show the within-subjects individual trajectories. In addition, we have added the expected outcome levels from Model 2a-b (linear effect of time) to highlight the overall change over time. There was considerable variability in scores in both baseline levels and across time among participants. However, at the betweensubject level, the average growth rate on the primary outcome variable (PCCSc) was positive $(b=0.14, p=0.001$ ), indicating improved sibling-rated quality of communication over time. Both SDQ-S and NAS showed a negative trend over time, indicating improved mental health from $\mathrm{T} 1$ to T3. In addition, the average slope for CD-knowledge (SKI) was slightly positive, indicating increased knowledge over time at the group level.

\section{Growth curve analyses}

Across all measures, the variances in intercept were significant $(\mathrm{p}<0.001$ for all outcome variables). However, the variances of the slopes were all non-significant, which means there was not significant variability between participants in change over time. Covariations between intercept and slope were also non-significant across measures.

Model fit for the primary outcome variable See Table 3 for parameter estimates from the three models for the PCCSc. When investigating linear effects of time (Model 2a), we found a small, significant positive change for siblings' perceived quality of parents' communication $[b=$ $0.14, p=0.001]$. This model had the best overall fit. As seen in Model 3a, adding gender of participating parent as a covariate did not improve model fit, suggesting that the gender of the parent did not have a significant effect on the levels of the communication variable.

Model fit for the secondary outcome variables See Table 4 for estimations of the four different models for all three secondary outcome variables (SDQ-S, NAS, and SKI). Regarding SDQ-S, the estimates of the model representing a linear effect of time (Model 2b) indicate that emotional and behavioral problem burden decreased significantly over time $(p=0.009)$. In Model $3 b$, which we found to have the best overall fit, it is seen that when adding parent-sibling communication as a time-varying covariate into the model, the effect of time is no longer significant $(p=0.061)$. This indicates that communication partly accounted for the positive change over time. Allowing sibling gender and age into the model (Model 4b), did not further improve model fit.

We observed the same pattern for NAS: we found a significant decrease in scores over time (Model 2b) $(p=$ 0.003 ), indicating improved adaptation to the $\mathrm{CD}$ from $\mathrm{T} 1$ to T3. The effect of time was no longer significant $(\mathrm{p}=$ 0.055) when adding PCCSc as a time-varying covariate (Model 3b). Again, this provided better model fit than the effect of time alone, suggesting that perceived quality of communication partly explained the level of adaptation problems. However, contrary to what we observed with SDQ-S, the age of the sibling seemed to have a mediating effect, as adding this covariate into the model (Model 4b) provided the best overall fit.

Lastly, in CD-knowledge (SKI), we found a significant improvement over time in the ability to explain the brother or sister's condition accurately (Model $2 b ; p=0.000$ ). For 

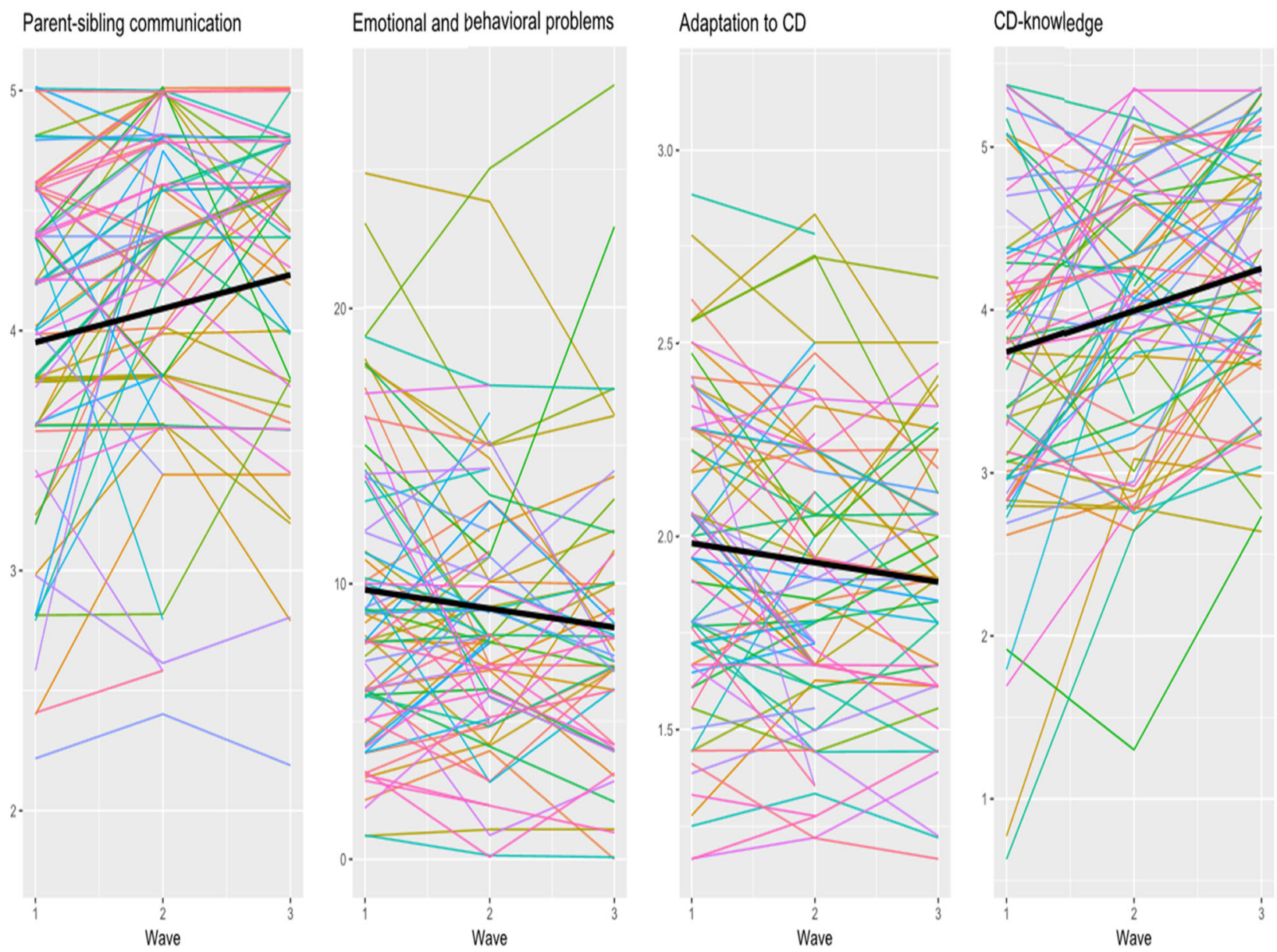

Fig. 3 Plots of observed individual change curves, with estimated change curve from model 2a-b (linear effect of time) superimposed in bold. CD chronic disorder

Table 3 Parent-sibling communication (PCCSc) growth curve modeling across T1-T3

\begin{tabular}{|c|c|c|c|c|c|c|}
\hline & \multicolumn{2}{|l|}{ Model 1a } & \multicolumn{2}{|l|}{ Model 2a } & \multicolumn{2}{|l|}{ Model 3a } \\
\hline & Est. & $95 \% \mathrm{CI}$ & Est. & $95 \% \mathrm{CI}$ & Est. & $95 \% \mathrm{CI}$ \\
\hline \multicolumn{7}{|l|}{ Fixed effects } \\
\hline Intercept & $4.06 * *$ & $(3.93,4.18)$ & $3.95 * *$ & $(3.81,4.09)$ & $3.95 * *$ & $(3.78,4.11)$ \\
\hline Slope & & & $0.14^{*}$ & $(0.06,0.22)$ & $0.14^{*}$ & $(0.06,0.22)$ \\
\hline PP gender ${ }^{\mathrm{a}}$ & & & & & 0.01 & $(-0.25,0.27)$ \\
\hline \multicolumn{7}{|l|}{ Model fit } \\
\hline AIC & 423.647 & & 415.058 & & 417.049 & \\
\hline
\end{tabular}

Results of growth curve modeling. Estimates (Est.) and 95\% confidence intervals (CI) with lower and upper bound

AIC Akaike information criterion, $P P$ participating parent

${ }^{*} p<0.01 ; * * p<0.001$

${ }^{\mathrm{a}}$ Effect of being a father this outcome variable, adding parent-sibling communication (Model 3b) did not improve model fit, indicating that the increased accuracy of participants' explanations of the CD cannot be attributed to perceived quality of communication [with participating parent]. On the other hand, adding age as a covariate (Model $4 \mathrm{~b}$ ) resulted in the best overall fit, i.e. higher age of participants was associated with more accurate CD-knowledge over time. 
Table 4 Growth curve models of secondary outcome variables (SDQ-S, NAS, and SKI) across T1-T3

\begin{tabular}{|c|c|c|c|c|c|c|c|c|}
\hline & \multicolumn{2}{|l|}{ Model 1b } & \multicolumn{2}{|l|}{ Model 2b } & \multicolumn{2}{|l|}{ Model 3b } & \multicolumn{2}{|l|}{ Model 4b } \\
\hline & Est. & $95 \% \mathrm{CI}$ & Est. & $95 \% \mathrm{CI}$ & Est. & $95 \% \mathrm{CI}$ & Est. & $95 \% \mathrm{CI}$ \\
\hline \multicolumn{9}{|c|}{$\begin{array}{l}\text { Emotional and behavioral } \\
\text { problems (SDQ-S) }\end{array}$} \\
\hline \multicolumn{9}{|l|}{ Fixed effects } \\
\hline Intercept & $9.27 * * *$ & $(8.29,10.24)$ & $9.76 * * *$ & $(8.71,10.81)$ & $15.01 * * *$ & $(11.35,18.67)$ & $17.60 * * *$ & $(11.17,24.03)$ \\
\hline Slope & & & $-0.68 * *$ & $(-1.18,-0.18)$ & -0.49 & $(-1.00,0.02)$ & -0.49 & $(-1.01,0.02)$ \\
\hline $\begin{array}{l}\text { Parent-sibling } \\
\text { communication } \\
\text { (PCCSc) }\end{array}$ & & & & & $-1.33 * *$ & $(-2.22,-0.44)$ & $-1.30 * *$ & $(-2.19,-0.41)$ \\
\hline Sibling age & & & & & & & -0.21 & $(-0.67,0.25)$ \\
\hline Sibling gender ${ }^{\mathrm{a}}$ & & & & & & & -0.69 & $(-2.58,1.20)$ \\
\hline \multicolumn{9}{|l|}{ Model fit } \\
\hline AIC & 1305.243 & & 1302.120 & & 1295.656 & & 1298.291 & \\
\hline \multicolumn{9}{|c|}{ Adaptation to CD (NAS) } \\
\hline \multicolumn{9}{|l|}{ Fixed effects } \\
\hline Intercept & $1.95 * * *$ & $(1.87,2.02)$ & $1.98 * * *$ & $(1.90,2.06)$ & $2.43 * * *$ & $(2.17,2.69)$ & $2.84 * * *$ & $(2.38,3.31)$ \\
\hline Slope & & & $-0.05^{* *}$ & $(-0.08,-0.02)$ & -0.03 & $(-0.07,0.00)$ & $-0.03 *$ & $(-0.07,0.00)$ \\
\hline $\begin{array}{l}\text { Parent-sibling } \\
\text { communication } \\
\text { (PCCSc) }\end{array}$ & & & & & $-0.11 * * *$ & $(-0.18,-0.52)$ & $-0.12 * * *$ & $(-0.18,-0.06)$ \\
\hline Sibling age & & & & & & & $-0.04 *$ & $(-0.07,0.00)$ \\
\hline Sibling gender ${ }^{\mathrm{a}}$ & & & & & & & 0.07 & $(-0.06,0.21)$ \\
\hline \multicolumn{9}{|l|}{ Model fit } \\
\hline AIC & 105.567 & & 101.265 & & 90.658 & & 89.190 & \\
\hline \multicolumn{9}{|l|}{ CD-knowledge (SKI) } \\
\hline \multicolumn{9}{|l|}{ Fixed effects } \\
\hline Intercept & $3.93 * * *$ & $(3.78,4.07)$ & $3.74 * * *$ & $(3.56,3.91)$ & $3.56 * * *$ & $(2.90,4.21)$ & $2.22 * * *$ & $(1.20,3.24)$ \\
\hline Slope & & & $0.26 * * *$ & $(0.16,0.36)$ & $0.25 * * *$ & $(0.15,0.35)$ & $0.27 * * *$ & $(0.16,0.38)$ \\
\hline $\begin{array}{l}\text { Parent-sibling } \\
\text { communication } \\
\text { (PCCSc) }\end{array}$ & & & & & 0.05 & $(-0.11,0.21)$ & 0.02 & $(-0.15,0.18)$ \\
\hline Sibling age & & & & & & & $0.11 * *$ & $(0.05,0.18)$ \\
\hline Sibling gender ${ }^{\mathrm{a}}$ & & & & & & & 0.16 & $(-0.11,0.44)$ \\
\hline \multicolumn{9}{|l|}{ Model fit } \\
\hline AIC & 493.452 & & 471.649 & & 473.427 & & 465.447 & \\
\hline
\end{tabular}

Results of growth curve modeling. Estimates (Est.) and 95\% confidence intervals (CI) with lower and upper bound

$C D$ chronic disorder, $S D Q-S$ strengths and difficulties questionnaire, self-report, $N A S$ negative adjustment scale, $S K I$ sibling knowledge interview, PCCSc parent-child communication scale, child version (parent communication subscale), AIC Akaike information criterion

$* p<0.05 ; * * p<0.01 ; * * * p<0.001$

${ }^{\mathrm{a}}$ Effect of being a boy

Estimates from the growth curve models for parent reported emotional and behavioral problems (SDQ-P) are provided in Appendix $\mathrm{B}$, showing that they partly reflected the models based on SDQ-S. As with sibling report, parent reported problems decreased over time. However, the decrease was only significant for father report $(\mathrm{p}=0.026)$. Unlike the model for sibling report, adding communication as a time-varying covariate for SDQ-P father report (Model 3b) did not improve model fit. Including sibling gender and age into the models (Model 4b) for SDQ-P did not improve model fit, like the models for sibling report.

\section{Effect Sizes}

Comparisons of mean scores in outcomes at the different assessment waves yielded medium to small effect sizes (Cohen 1988). See Table 5 for details. 
Table 5 Mean scores and effect sizes (Cohen's d) of differences in means across

assessment waves

\begin{tabular}{lllllll}
\hline Variable & Measure & T1 mean $(n ; s d)$ & T2 mean $(n ; s d)$ & T3 mean $(n ; s d)$ & $\begin{array}{l}d \\
(\mathrm{~T} 2 ; \mathrm{T} 1)\end{array}$ & $\begin{array}{l}d \\
(\mathrm{~T} 3 ; \mathrm{T} 1)\end{array}$ \\
\hline $\begin{array}{l}\text { Parent-sibling } \\
\text { communication }\end{array}$ & PCCSc & $3.97(97 ; 0.73)$ & $4.17(77 ; 0.78)$ & $4.33(55 ; 0.77)$ & 0.26 & 0.48 \\
$\begin{array}{l}\text { Emotional/behavioral problems } \\
\text { Sibling self-report }\end{array}$ & SDQ-S & $9.86(98 ; 5.45)$ & $8.68(76 ; 4.82)$ & $8.19(56 ; 5.38)$ & 0.23 & 0.31 \\
\multicolumn{1}{l}{$\begin{array}{l}\text { Mother report } \\
\text { Father report }\end{array}$} & SDQ-P & $9.20(93 ; 6.69)$ & $8.59(74 ; 6.58)$ & $7.92(54 ; 5.28)$ & 0.09 & 0.21 \\
Adaptation to CD & SDQ-P & $9.27(90 ; 6.98)$ & $8.65(70 ; 5.64)$ & $7.86(47 ; 4.62)$ & 0.10 & 0.24 \\
CD-knowledge & SKI & $1.99(98 ; 0.41)$ & $1.90(77 ; 0.39)$ & $1.89(54 ; 0.35)$ & 0.22 & 0.26 \\
\hline
\end{tabular}

$n$ sample size, $s d$ standard deviation, $C D$ chronic disorder, $P C C S s$ parent-child communication scale, child version (parent communication subscale), $S D Q-S$ strengths and difficulties questionnaire, self-report, $S D Q-P$ strengths and difficulties questionnaires, parent report, NAS negative adjustment scale, $S K I$ sibling knowledge interview

\section{Discussion}

We evaluated a novel five-session intervention (SIBS) for siblings of children with $\mathrm{CD}$ and one of their parents. Both siblings' and parents' evaluation of the intervention indicated high acceptability. Overall, analyses of outcomes showed significant improvement over time in quality of parent-sibling communication, the primary target of the intervention, and in sibling reports of emotional and behavioral problems, adaptation to the $\mathrm{CD}$, and CD-knowledge. Furthermore, the observed improvements in the siblingreported mental health measures were partly accounted for by the quality of parent-sibling communication. Our results hold promise for SIBS, although the uncontrolled design prevents us from establishing that the intervention caused these changes.

Group leader adherence to the intervention manual was good, supporting the feasibility of the intervention. Further, conducting a brief intervention enabled non-demanding participation of families being under considerable strain. The large number of families participating and retaining throughout the intervention sessions indicated SIBS as a feasible intervention. However, high attrition from baseline to follow-up challenges the feasibility of the intervention as a research trial.

In terms of possible beneficial outcomes of SIBS, we found improved quality of communication across all time points. Our assumption was that teaching parents about supportive ways to respond to siblings' expressions of challenges they experience due to the $\mathrm{CD}$ would improve parent-sibling communication. This assumption was supported. As such, including a psychoeducational component that focuses on strengthening parent-sibling communication in interventions seems to be beneficial. Further research is needed to examine the effects of interventions targeting parent-sibling communication on sibling mental health.

Both mothers and fathers participated in SIBS, however only one parent participated per sibling. Our finding that sibling-rated communication with both genders of parents improved may indicate a strength of the intervention. It would be interesting for future research to examine the role of different conjunctions of the parent-sibling dyads (e.g., mother-daughter, father-daughter), as previous research has pointed to gender differences both in children's emotional expressions (e.g., O'Kearny and Dadds 2004) and that the nature of parent-child emotional dialogues may be dependent on child and parent gender (e.g., Adams et al. 1995). Further, it may be valuable to include both parents' and siblings' report of the quality of parent-sibling communication. In order to strengthen the psychoeducational material of SIBS, it would also be valuable to investigate more deeply, i.e. through observational measures, how parents relate to it and turn the key messages into practice when talking to siblings. It would be particularly interesting to utilize measures that capture how parents respond to the children's emotional expressions and whether space is provided for further elaboration of the siblings' thoughts and feelings about their experiences related to having a brother or sister with a CD.

Growth curve modeling of the sibling mental health measures (i.e., SDQ-S and NAS) showed decreases in problem burden over time. Including parent-sibling communication as a covariate provided better model fit, rendering the effect of time no longer significant. A plausible interpretation is that the quality of parent-sibling communication is a central factor for siblings' mental health. The possible role of communication is further supported by the negative correlations found between levels of parent-sibling communication and scores on both SDQ-S and NAS at all 
time points. These findings support our assumption of the key role parent-sibling communication plays for sibling mental health and are in line with previous studies suggesting that emotional support from parents is associated with better adaptation in siblings to CD in a brother or sister (e.g., Incledon et al. 2015; Long et al. 2013). The findings also make sense considering the vast research evidence from normative samples linking the emotional responsiveness of parents to child adjustment (e.g., Gottman et al. 1996; McCarty et al. 2005). Nevertheless, we were not able to conclude that the observed positive change in the communication variable caused the observed change in the mental health variables. Future controlled studies with larger samples are needed to further investigate the association between parent-sibling communication and sibling mental health.

Although sibling emotional and behavioral problems decreased over time for all informants, the decrease was significant only for sibling and father report, and not for mother report. Sibling research has generally been criticized for relying mainly on parent report (e.g., Giallo et al. 2012), due to documented discrepancies between parent and sibling report (Guite et al. 2004; Houtzager et al. 2005). Therefore, our finding of improved emotional and behavioral problems from siblings' perspective is an important aspect of the interventions' potential. Several factors may impact parents' rating of their typically developing children's mental health, such as levels of stress and depression, which is documented to be higher in parents of children with CDs than in norms (e.g. Cousino and Hazen 2013; Singer 2006). In our study, there was higher overlap between sibling-father report compared to sibling-mother report on the SDQ scores over time. Mother report on SDQ$\mathrm{P}$ has been associated with emotional distress and burden of care (Taylor et al. 2001). Thus, given the tendency of CDs in children to be linked to more experienced distress in mothers than in fathers (e.g., Hansen et al. 2012; VrijmoetWiersma et al. 2008), SDQ-P for mothers may be more associated with mothers' own psychological health. However, more research is needed to disentangle possible explanations for the differences between mother and father report on this variable.

CD-knowledge also improved significantly over time. However, this outcome was not significantly correlated with parent-sibling communication and adding communication did not improve model fit for CD-knowledge trajectories. This lack of association between CD-knowledge and communication may be due to the fact that the focus in SIBS was not to teach the parents how to provide accurate information and explanations about the $\mathrm{CD}$, rather it was to strengthen parents' awareness on siblings' thoughts and perceptions of CD-related topics and to enable them to relate to these in an explorative and supportive manner.
It is important to note that although we found significant changes in all sibling-reported outcome variables from baseline to post intervention, effect sizes were all small or moderate. However, initial self-reports of mental health symptoms were low and rarely within the borderline or clinical range, and baseline reports of parent-sibling communication reflected that the quality of communication in these families was perceived as good before joining SIBS. Hence, the potential for change was limited and large effect sizes were not to be expected.

In this study, the mean scores on sibling- and parentreported SDQ at baseline were similar to previous sibling studies (e.g., Giallo et al. 2012; Taylor et al. 2001), showing that siblings tend to be within the upper limits of the normative range. Mean baseline scores on sibling adaption to the $\mathrm{CD}$ and CD-knowledge were also similar to the reports of previous sibling studies (Lobato and Kao 2002, 2005; Lobato et al. 2005). PCCS has, to the best of our knowledge, previously not been applied in sibling studies. Previous intervention trials for siblings have been criticized for not applying explicit inclusion/exclusion criteria for siblings (Tudor and Lerner 2015). Yet, as there is still a lack of consensus on the specific factors that may identify siblings at risk (Tudor and Lerner 2015), we considered it premature to incorporate other selection criteria for study inclusion at this stage. A previous sibling intervention study utilizing SDQ found change in parent-reported scores to be predicted by participants' initial status (Roberts et al. 2016). Hence, the implication of baseline scores for intervention effects requires more investigation and further research is needed to identify factors associated with siblings and families representing elevated problem levels and that may be in particular need of services (Roberts et al. 2016).

We revealed large variability in baseline levels on selected outcome measures in this study, which implies that siblings as next of kin represent a heterogeneous group. Investigating predictors for the observed variance in baseline levels across measures could also provide important knowledge about mediating factors of risk in siblings, and, correspondingly, should be further examined within a rigorously controlled design. Future studies need to disentangle if sibling interventions are optimally delivered as treatment, i.e., for siblings with symptoms in the clinical range, as indicated prevention, i.e., for siblings with borderline clinical symptom levels, or as universal prevention, i.e., for all siblings. Based on our findings regarding levels of mental health problems, and those of others (e.g., Vermaes et al. 2012), indicated prevention may be the level of intervention that optimally fits the target group. In the continuation of the development and implementation of SIBS, it will be an important task to specify selection criteria that are based on the current knowledge on documented risk factors in siblings, to 
enhance the probability that siblings most in need of services and that most likely will benefit from the intervention are reached.

\section{Limitations}

The present study has limitations. The main limitation is the lack of a controlled design. Furthermore, the sample was heterogeneous in terms of type of CD and we did not assess severity criteria of the CDs. We included siblings with a wide age range and our sample comprised mainly parents with high socio-economic status. Future evaluation trials of the intervention should strive for more diversity in participating families in terms of socio-economic status and ethnicity. SIBS was carried out during family courses at a national specialist center or a camp setting, and although sharing some common features, all these settings included variability in timeframe, staff, physical location, number of participants as well as program and leisure content apart from SIBS that may have impacted the outcome measures trajectories. Although our examination of nesting of data at intervention level did not yield any significant intraclass correlations, a study within a controlled design is necessary to limit the impact of such confounding variables. Furthermore, while the inclusion of follow-up assessments represents a strength of the present study, this longitudinal design also led to a drop in respondents from baseline due to missing data. As families of children with CDs represent families living under continuous strain, recruitment for time-demanding longitudinal research remains a challenge for the field.

\section{Conclusion}

The outcome data from this first trial of SIBS are encouraging, in that we found significant improvement over time in sibling-reported parent-sibling communication, emotional and behavioral functioning and adaptation to the $\mathrm{CD}$, as well as in CD-knowledge. In addition, perceived quality of parent-sibling communication seemed to partly account for improvement in sibling-reported mental health symptoms. Measures of participant satisfaction indicated high approval of SIBS among participants. Our findings suggest that parent-sibling communication may be central to siblings' mental health and that siblings may benefit from interventions directed at the parent-sibling dyad, focusing on strengthening parent-sibling communication and empowering parents in their provision of emotional and informational support to siblings.

Acknowledgements Open Access funding provided by University of Oslo (incl Oslo University Hospital).

Author Contributions Y.B.H. designed and executed the study, completed data analyses, and wrote the paper. N.O.C. analyzed the data and wrote part of the results. K.W.F. designed and executed the study, assisted with the data analyses, and collaborated in the writing and editing of the final manuscript. W.K.S. contributed to designing the study and collaborated in the writing and editing of the final manuscript. S.M. designed and executed the study and collaborated in the editing of the final manuscript. T.M.V. designed and executed the study and collaborated in the writing and editing of the final manuscript. All authors read and approved the final manuscript.

\section{Compliance with Ethical Standards}

Conflict of Interest The authors declare that they have no conflict of interest.

Ethics Approval All procedures performed were in accordance with the ethical standards of the Regional Committees for Medical and Health Research Ethics (reference number 2011/2514) and with the 1964 Helsinki declaration and its later amendments or comparable ethical standards.

Informed Consent Written informed consent was obtained from the parents and oral consent was obtained from the children.

Publisher's note Springer Nature remains neutral with regard to jurisdictional claims in published maps and institutional affiliations.

Open Access This article is licensed under a Creative Commons Attribution 4.0 International License, which permits use, sharing, adaptation, distribution and reproduction in any medium or format, as long as you give appropriate credit to the original author(s) and the source, provide a link to the Creative Commons license, and indicate if changes were made. The images or other third party material in this article are included in the article's Creative Commons license, unless indicated otherwise in a credit line to the material. If material is not included in the article's Creative Commons license and your intended use is not permitted by statutory regulation or exceeds the permitted use, you will need to obtain permission directly from the copyright holder. To view a copy of this license, visit http://creativecommons. org/licenses/by/4.0/.

\section{Appendix}

Table 6

Table 7 


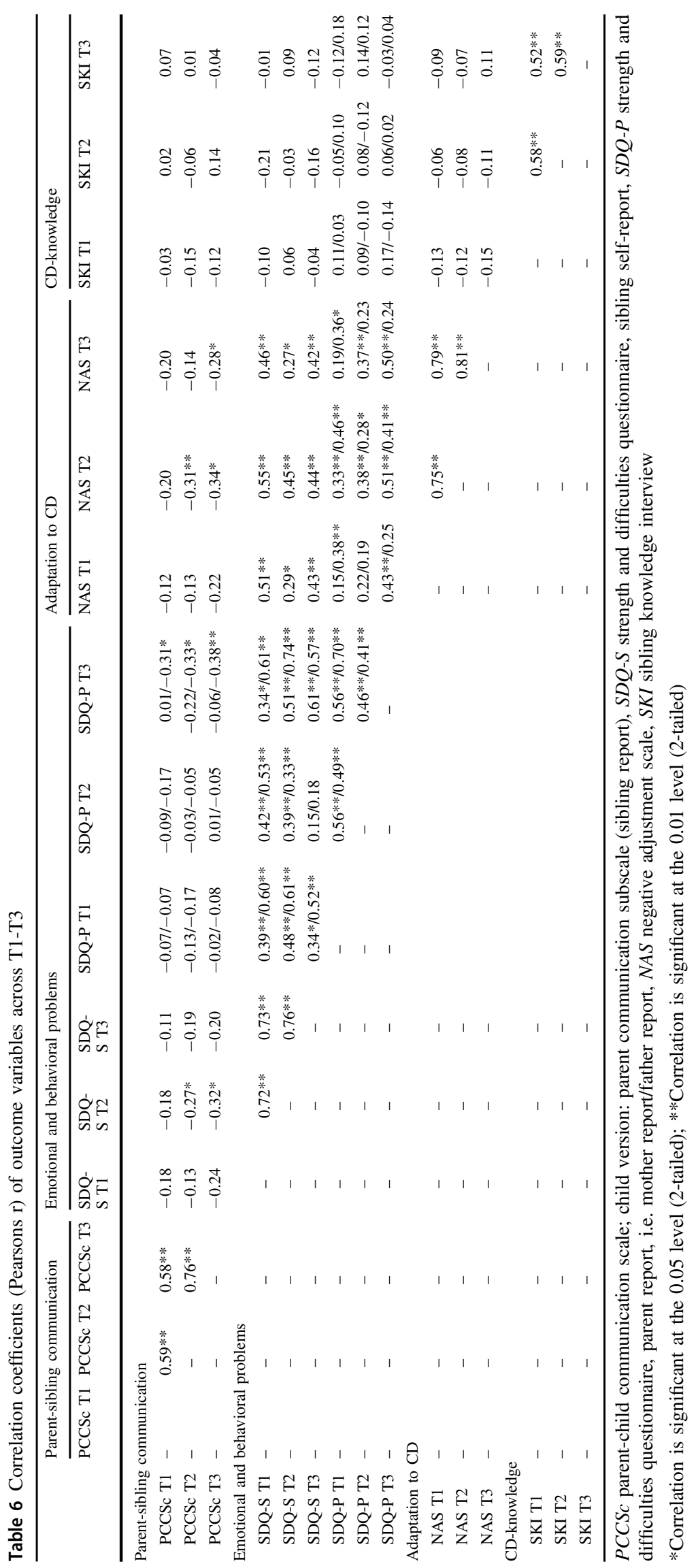


Table 7 Growth curve models of secondary outcome variable SDQ-P across T1-T3

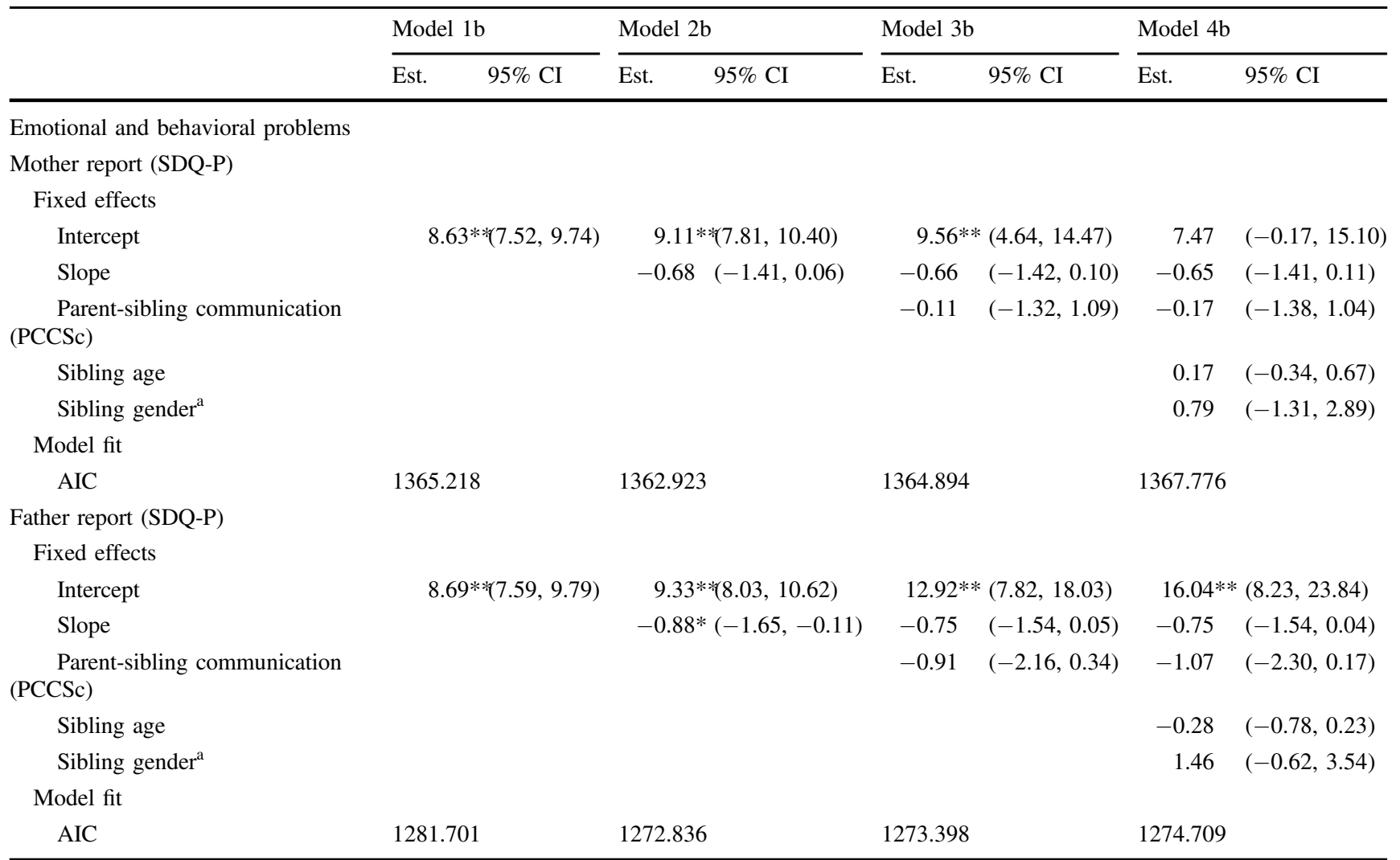

Results of growth curve modeling. Estimates (Est.) and 95\% confidence intervals (CI) with lower and upper bound

$S D Q-P$ strengths and difficulties questionnaire, parent report, $P C C S c$ parent-child communication scale, child version (parent communication subscale), AIC Akaike information criterion

$* p<0.05 ; * * p<0.001$

${ }^{\mathrm{a}}$ Effect of being a boy

\section{References}

Adams, S., Kuebli, J., Boyle, P. A., \& Fivush, R. (1995). Gender differences in parent-child conversations about past emotions: a longitudinal investigation. Sex Roles, 33, 309-323.

Akaike, H. (1974). A new look at the statistical model identification. IEEE Transactions on Automatic Control, 19, 716-723. https:// doi.org/10.1109/TAC.1974.1100705.

Aldridge, M., \& Wood, J. (1997). Talking about feelings: young children's ability to express emotions. Child Abuse \& Neglect, 21, 1221-1233.

Barnes, H., \& Olson, D. (1985). Parent-adolescent communication and the circumplex model. Child Development, 56, 438-447. https:// doi.org/10.2307/1129732.

Brennan, C., Hugh-Jones, S., \& Aldridge, J. (2012). Pediatric lifelimiting conditions: coping and adjustment in siblings. Journal of Health Psychology, 18, 813-824. https://doi.org/10.1177/ 1359105312456324.

Cicchetti, D., \& Toth, S. L. (1998). The development of depression in children and adolescents. American Psychologist, 53, 221-241. https://doi.org/10.1037/0003-066X.53.2.221.

Cohen, J. (1988). Statistical power analysis for the behavioral sciences. 2nd ed. Hillsdale, NJ: Lawrence Erlbaum Associates.

Conduct Problems Prevention Research Group (CPPRG). (1994). http://fasttrackproject.org/techrept/p/pcp/index.php.
Cooke, J., \& Semmens, C. (2010). The development and evaluation of a support group for siblings of children on the autism spectrum. Good Autism Practice, 11, 23-30.

Cousino, M. K., \& Hazen, R. A. (2013). Parenting stress among caregivers of children with chronic illness: a systematic review. Journal of Pediatric Psychology, 38, 809-828. https://doi.org/10. 1093/jpepsy/jsto49.

Fivush, R. (2007). Maternal reminiscing style and children's developing understanding of self and emotion. Clinical Social Work Journal, 35, 37-46. https://doi.org/10.1007/s10615-006-0065-1.

Gelman, A., \& Hill, J. (2007). Data analysis using regression and multilevel/hierarchical models. Cambridge: Cambridge University Press.

Gentzler, A. L., Contreras-Grau, J. M., Kerns, K. A., \& Weimer, B. L. (2005). Parent-child emotional communication and children's coping in middle childhood. Social Development, 14, 591-612. https://doi.org/10.1111/j.1467-9507.2005.00319.x.

Giallo, R., Gavidia-Payne, S., Minett, B., \& Kapoor, A. (2012). Sibling voices: the self-reported mental health of siblings of children with a disability. Clinical Psychologist, 16, 36-43. https://doi. org/10.1111/j.1742-9552.2011.00035.x.

Goodman, R. (2001). Psychometric properties of the strengths and difficulties questionnaire. Journal of the American Academy of Child and Adolescent Psychiatry, 40, 1337-1345. https://doi.org/ 10.1097/00004583-200111000-00015. 
Goodman, R., Ford, T., Richards, H., Gatward, R., \& Meltzer, H. (2000). The development and well-being assessment: description and initial validation of an integrated assessment of child and adolescent psychopathology. Journal of Child Psychology and Psychiatry, 41, 645-655. https://doi.org/10.1111/j.1469-7610. 2000.tb02345.x.

Goodman, R., \& Scott, S. (1999). Comparing the strengths and difficulties questionnaire and the child behavior checklist: is small beautiful? Journal of Abnormal Child Psychology, 27, 17-24. https://doi.org/10.1023/A:1022658222914.

Gottman, J. M., Katz, L. F., \& Hooven, C. (1996). Parental metaemotion philosophy and the emotional life of families: theoretical models and preliminary data. Journal of Family Psychology, 10, 243-268. https://doi.org/10.1037//0893-3200.10.3.243.

Guite, J., Lobato, D., Kao, B., \& Plante, W. (2004). Discordance between sibling and parent reports of the impact of chronic illness and disability on siblings. Children's Health Care, 33, 77-92. https://doi.org/10.1207/s15326888chc3301_5.

Guo, S. (2005). Analyzing grouped data with hierarchical linear modelling. Children and Youth Services Review, 27, 637-652. https://doi.org/10.1016/j.childyouth.2004.11.017.

Hansen, J. A., Schwartz, D. D., Weissbrod, C., \& Taylor, W. P. (2012). Paternal involvement in pediatric Type 1 diabetes: father's and mother's psychological functioning and disease management. Families, Systems, \& Health, 30, 47-59. https://doi. org/10.1037/a0027519.

Hartling, L., Milne, A., Tjosvold, L., Wrightson, D., Gallivan, J., \& Newton, A. S. (2014). A systematic review of interventions to support siblings of children with chronic illness or disability. Journal of Paediatrics and Child Health, 50, E26-E38. https:// doi.org/10.1111/j.1440-1754.2010.01771.x.

Haukeland, Y. B., Fjermestad, K. W., Mossige, S., \& Vatne, T. M. (2015). Emotional experiences among siblings of children with rare disorders. Journal of Pediatric Psychology, 40, 712-720. https://doi.org/10.1093/jpepsy/jsv022.

Heck, R. H., \& Thomas, S. L. (2015). An introduction to multilevel modeling techniques: MLM and SEM approaches using Mplus. 3rd ed. NY: Routledge.

Hilton, B. A., \& Gustavson, K. (2002). Shielding and being shielded: children's perspectives on coping with their mother's cancer and chemotherapy. Canadian Oncology Nursing Journal, 12, 198-206.

Houtzager, B. A., Grootenhuis, M. A., Caron, H. N., \& Last, B. F. (2005). Sibling self-report, parental proxies and qualities of life: the importance of multiple informants for siblings of a critically ill child. Pediatric Hematology and Oncology, 22, 25-40. https:// doi.org/10.1080/08880010590896233.

Houtzager, B. A., Grootenhuis, M. A., \& Last, B. F. (2001). Supportive groups for siblings of pediatric oncology patients: impact on anxiety. Psycho-Oncology, 10, 315-324.

IBM Corp. (2017). IBM SPSS Statistics for Windows, Version 22.0. Armonk, NY: IBM Corp.

Incledon, E., Williams, L., Hazell, T., Heard, T. R., Flowers, A., \& Hiscock, H. (2015). A review of factors associated with mental health in siblings of children with chronic illness. Journal of Child Health Care, 19, 182-194. https://doi.org/10.1177/ 1367493513503584

Jackson, S., Bijstra, J., Oostra, L., \& Bosma, H. (1998). Adolescents' perceptions of communication with parents relative to specific aspects of relationships with parents and personal development. Journal of Adolescence, 21, 305-322. https://doi.org/10.1006/ja do.1998.0155.

Knecht, C., Hellmers, C., \& Jun, S. M. (2015). The perspective of siblings of children with chronic illness: a literature review. Journal of Pediatric Nursing, 30, 102-116. https://doi.org/10. 1016/j.pedn.2014.10.010.
Little, R. J. A. (1986). A test of missing completely at random for multivariate data with missing values. Journal of the American Statistical Association, 83, 1198-1202. https://doi.org/10.1080/ 01621459.1988.10478722.

Lobato, D. J., \& Kao, B. T. (2002). Integrated sibling-parent group intervention to improve sibling knowledge and adjustment to chronic illness and disability. Journal of Pediatric Psychology, 27, 711-716. https://doi.org/10.1093/jpepsy/27.8.711.

Lobato, D. J., \& Kao, B. T. (2005). Brief report: family-based group intervention for young siblings of children with chronic illness and developmental disability. Journal of Pediatric Psychology, 30, 678-682. https://doi.org/10.1093/jpepsy/jsi054.

Lobato, D. J., Kao, B. T., \& Plante, W. (2005). Latino sibling knowledge and adjustment to chronic disability. Journal of Family Psychology, 19, 625-632. https://doi.org/10.1027/08933200.19.4.625.

Long, K. A., Lobato, D. J., Kao, B. T., Plante, W., Grullón, E., Cheas, L., Houck, C., \& Seifer, R. (2013). Perceptions of emotion expression and sibling-parent emotion communication in Latino and non-Latino white siblings of children with intellectual disabilities. Journal of Pediatric Psychology, 38, 551-562. https:// doi.org/10.1093/jpepsy/jst012.

Lucas-Thompson, R. G., Dumitrache, A., \& Sparks, A. Q. (2017). Appraisals of interparental conflict and change in attention to emotion after exposure to marital conflict. Journal of Child and Family Studies, 26, 2175-2181. https://doi.org/10.1007/s10826017-0721-9.

McCarty, C. M., \& Doyle, S. R. (2001). Parent-child communication (child) (Fast Track Project Technical Report). http://www.fasttra ckproject.org.

McCarty, C. A., Zimmermann, F. J., Diguiseppe, D. L., \& Christakis, D. A. (2005). Parental emotional support and subsequent internalizing and externalizing problems among children. Journal of Developmental \& Behavioral Pediatrics, 26, 267-275. https:// doi.org/10.1097/00004703-200508000-00002.

McCullough, K., \& Simon, S. R. (2011). Feeling heard: a support group for siblings of children with developmental disabilities. Social Work with Groups, 34, 320-329. https://doi.org/10.1080/ 01609513.2011.558819.

Murphy, L. K., Murray, C. B., \& Compas, B. E. (2017). Topical review: Integrating findings on direct observation of family communication in studies comparing pediatric chronic illness and typically developing samples. Journal of Pediatric Psychology, 42, 85-94. https://doi.org/10.1093/jpepsy/jsw051.

O'Kearny, R., \& Dadds, M. (2004). Developmental and gender differences in the language for emotions across the adolescent years. Cognition and Emotion, 18, 913-938. https://doi.org/10.1080/ 02699930341000356.

Pek, J. C. X. (2006). Parent-child communication, child report (Fast Track Project Technical Report). http://www.fastrackproject.org.

Riekert, K. A., Wiener, L. S., \& Battles, H. (1999). Prediction of psychological distress in school-age children with HIV. Children's Health Care, 28, 201-220.

Roberts, M. A., Ejova, A., Giallo, R., Strohm, K., \& Lillie, M. E. (2016). Support group programme for siblings of children with special needs: predictors of improved emotional and behavioral functioning. Disability and Rehabilitation, 38, 2063-2072. https://doi.org/10.3109/09638288.2015.1116621.

Sahler, O. J. Z., \& Carpenter, P. J. (1989). Evaluation of a camp program for siblings of children with cancer. American Journal of Diseases of Children, 143, 690-696.

Singer, G. H. (2006). Meta-analysis of comparative studies of depression in mothers of children with and without developmental disabilities. American Journal on Mental Retardation, 122, 155-169. https://doi.org/10.1352/0895-8017(2006)111[155: MOCSOD]2.0.CO;2. 
Smith, T., \& Perry, A. (2005). A sibling support group for brothers and sisters of children with autism. Journal of Developmental Disabilities, 11, 77-88.

Stanton, A. L., Revenson, T. A., \& Tennen, H. (2007). Health psychology: psychological adjustment to chronic disease. The Annual Review of Psychology, 58, 565-592. https://doi.org/10. 1146/annurev.psych.58.110405.085615.

Taylor, V., Fuggle, P., \& Charman, T. (2001). Well sibling psychological adjustment to chronic physical disorder in a sibling: how important is maternal awareness of their illness attitudes and perceptions? Journal of Child Psychology and Psychiatry, 42, 953-962. https://doi.org/10.1017/S0021963001007752.

Tudor, M. E., \& Lerner, M. D. (2015). Intervention and support for siblings of youth with developmental disabilities. Clinical Child and Family Psychology Review, 18, 1-23. https://doi.org/10. 1007/s10567-014-0175-1.

United Nations Children's Fund (2013). UNICEF the state of the world's children: children with disabilities. New York: United Nations. www.data.unicef.org/resources/the-state-of-the-worldschildren-2013-children-with-disabilities/.

Vatne, T. M., Haukeland, Y. B., Mossige, S., \& Fjermestad, K. W. (2019). The development of a joint parent-child intervention for siblings of children with chronic disorders. Fokus på Familien, 47, 20-35. https://doi.org/10.18261/issn.0807-7487-2019-01-03.

Vatne, T. M., Helmen, I. Ø., Bahr, D., Kanavin, Ø., \& Nyhus, L. (2015). "She came out of mum's tummy the wrong way": (Mis)
Conceptions among siblings of children with rare disorders. Journal of Genetic Counselling, 24, 247-258. https://doi.org/10. 1007/s10897-014-9757-9.

Vermaes, I. P. R., van Susante, A. M. J., \& van Bakel, H. J. A. (2012). Psychological functioning of siblings in families of children with chronic health conditions: a meta-analysis. Journal of Pediatric Psychology, 37, 166-184. https://doi.org/10.1093/jpepsy/ jsro8110.1017/S0021963001007752.

Vostanis, P. (2006). Strengths and difficulties questionnaire: research and clinical applications. Current Opinion in Psychiatry, 19, 367-372. https://doi.org/10.1097/01.yco.0000228755.72366.05.

Vrijmoet-Wiersma, C. M. J., van Klink, J. M. M., Kolk, A. M., Koopman, H. M., Ball, L. M., \& Egeler, R. M. (2008). Assessment of parental psychological stress in pediatric cancer: a review. Journal of Pediatric Psychology, 33, 694-706. https:// doi.org/10.1093/jpepsy/jsn007.

Williams, P. D., Williams, A. R., Graff, J. C., Hanson, S., Stanton, A., Hafeman, C., \& Sanders, S. (2003). A community-based intervention for siblings and parents of children with chronic illness or disability: the ISEE study. The Journal of Pediatrics, 143, 386-393. https://doi.org/10.1067/S0022-3476(03)00391-3.

Zajdel, R. T., Bloom, J. M., Fireman, G., \& Larsen, J. T. (2013). Children's understanding and experience of mixed emotions: the roles of age, gender, and empathy. The Journal of Genetic Psychology, 174, 582-603. https://doi.org/10.1080/00221325.2012. 732125 . 